\title{
Why is Manufacturing Trade Rising Even as Manufacturing Output is Falling?
}

\author{
Raphael Bergoeing, Tim Kehoe, Vanessa Strauss-Kahn and Kei-Mu Yi*
}

January 2004

Raphael Bergoeing, Centro de Economia Aplicada, Universidad de Chile, Av. República 701, Santiago de Chile, CHILE; Ph: +56/2/678 4524; fax: +56/2/689 7895; email: raphaelb@ dii.uchile.cl

Timothy J. Kehoe, Department of Economics, University of Minnesota, $27119^{\text {th }}$ Avenue South, Minneapolis, MN 55455; Ph: 612-625-1589; fax:1-612-624-0209; email: tkehoe@econ.umn.edu

Vanessa Strauss-Kahn, Department of Economics, INSEAD, boulevard de Constance, 77305

Fontainebleau Cedex, FRANCE; Ph: +33 16072 4239; fax: +33 1607455 95; email: vanessa.strausskahn@insead.edu

Kei-Mu Yi, Research Department, Federal Reserve Bank of Philadelphia, 10 Independence Mall, Philadelphia, PA, 19106-1574; Ph: (215) 574-3809; fax: (215) 574-4303; email:

Kei-Mu.Yi@phil.frb.org

JEL Classification code: F1, F4

Keywords: manufacturing output, manufacturing trade, vertical specialization 


\begin{abstract}
For the OECD as whole, as well as for the U.S., manufacturing exports have been rising, while manufacturing output (both expressed as a share of total GDP) has been falling. We examine the prevalence of this puzzling fact across individual OECD countries, as well as for particular sub-industries of manufacturing. We then address whether the standard international trade paradigms are capable of quantitatively resolving the puzzle. We extend the basic monopolistic competition-cum-Heckscher-Ohlin model to allow for non-homothetic preferences, non-unitary demand elasticities and for changing trade barriers and country-size distributions over time. In a calibrated version of the model, we find that while the extended model can replicate the puzzle qualitatively, it cannot do so quantitatively. We suggest that the unexplained part of the puzzle may be due to vertical specialization - the phenomenon by which countries specialize in particular stages of a good's production sequence - leading to "back-and-forth" trade, and creating a distinction between 'gross' trade and value-added trade. The standard trade paradigms only include value-added trade.
\end{abstract}

JEL Code: F1, F4 
During the past 30 years, almost all developed countries have experienced increases in manufacturing exports as a share of GDP. Figure 1 shows that, among 22 OECD countries, only one has experienced a decrease. ${ }^{1}$ For the OECD overall, the manufacturing export share of GDP rose at an annual rate of 1.4 percent per year between 1970 and 1998. Figure 1 also shows, however, that during the same period, all but three countries have experienced declines in manufacturing value-added as a share of GDP. Again, for the OECD overall, this share declined at a rate of 1.3 percent per year.

These two facts are important and puzzling. Important, because manufacturing's significance in world trade continues to rise. As of 2001, manufacturing constituted $89 \%$ of OECD merchandise exports. Puzzling, because they imply that most of the world's major economies are exporting more and more of goods that they are producing less and less of.

The goal of this paper is to examine whether these facts can be jointly explained by international trade theory. We focus on one of the workhorse models of international trade, Helpman and Krugman's (1985) version of the monopolistic competition model. To generate implications for changes in manufacturing exports and manufacturing GDP, we subject the model to three types of "shocks" that capture essential features of the global economy over the past three decades: increases in manufacturing productivity, increases in non-manufacturing productivity, and decreases in trade barriers. We assess whether any of these shocks is capable of replicating the above pattern.

Our work is related to and builds on Bergoeing and Kehoe (2003). ${ }^{2}$ Bergoeing and Kehoe (BK) develop a Heckscher-Ohlin cum monopolistic competition model, calibrate it to OECD data between 1961 and 1990, and then quantitatively assess whether the model can generate the above two and other key trade facts. They conclude that the model cannot. Our 
focus is more on the qualitative properties of the monopolistic competition model: what can we learn from this model about what it will take to explain the two facts? In addition, we extend the BK framework by including trade barriers.

We have two main results: (1) Neither manufacturing nor non-manufacturing productivity shocks can deliver the two facts. This is true under free trade or under positive transport costs. With these shocks, output and exports move together; (2) When we allow for transport costs in the model to decline over time, (our globalization scenario), we can qualitatively generate the two facts for one or both countries. This is particularly true when the elasticity of substitution between manufacturing and non-manufacturing goods is low. We question whether this scenario can explain the two facts quantitatively, however.

We conclude by suggesting that vertical specialization — as defined by Hummels, Ishii, and Yi (2001), when a good is produced in multiple stages in multiple countries - can resolve the puzzle.

\section{MODEL}

The production side of our model is the same as in Helpman and Krugman (1985). There are two countries; two sectors, a non-manufacturing sector and a manufacturing sector; and a fixed endowment of a single factor, labor $(L)$. All goods are final goods. The nonmanufacturing sector consists of a single good produced by constant returns to scale, while the manufacturing sector consists of differentiated varieties with each variety produced according to increasing returns. The technologies for these two types of goods are identical across the two countries, and are 


$$
\begin{aligned}
& Y_{n}=A_{n} \ell_{n}, \\
& Y_{m}(z)=\max \left[A_{m} \ell_{m}(z)-F, 0\right],
\end{aligned}
$$

where $A_{n}$ and $A_{m}$ are non-manufacturing and manufacturing productivity, $z$ indexes variety, $\ell_{n}$ and $\ell_{m}(z)$ are labor inputs, and $F$ is a fixed cost.

Preferences are also identical across countries. Following BK, we allow for nonhomothetic utility and for non-unitary elasticities of substitution between sectors:

$$
U=\frac{1}{\eta}\left[\beta_{n}\left(c_{n}+\gamma\right)^{\eta}+\beta_{m}\left(\int_{D_{m}} c_{m}(z)^{\rho}\right)^{\frac{\eta}{\rho}}-1\right],
$$

where $c_{n}$ and $c_{m}(z)$ are consumption levels $\beta_{n}$ and $\beta_{m}$ sum to $1, \rho$ governs the elasticity of substitution between manufacturing varieties, $\eta$ governs the price elasticity of demand and the elasticity of substitution between manufacturing and non-manufacturing, and $\gamma$ governs the income elasticity of demand and the degree of non-homotheticity. $D_{m}$ is the measure of manufactured goods produced worldwide. As $\eta$ approaches 1 , the price elasticity of demand approaches infinity. If $\gamma>0$, then non-manufactured goods are valued as luxury goods.

When $\eta=\gamma=0$, then

$$
U=\beta_{n} \log \left(c_{n}\right)+\beta_{m} \log \left(\int_{D_{m}} c_{m}(z)^{\rho}\right)^{\frac{1}{\rho}} .
$$

Trade barriers are modeled as iceberg transport costs, which can be interpreted as tariffs whose revenues are thrown away or spent in a non-distorting manner. To import 1 unit of a good, $\tau>1$ units must be shipped.

Our model does not yield analytical solutions except in special cases. There is, however, 
a very simple and useful expression for the manufacturing output share of GDP of country i,

$$
\mu_{t}=\frac{D_{m}^{i} F}{A_{m}(1-\rho) L_{i}} .
$$

In logarithms, the change in the manufacturing share equals the change in the interval of manufacturing goods produced minus the change in manufacturing productivity.

\section{IMPLICATIONS UNDER FREE TRADE}

Because technologies are identical across countries, under free trade, wages are equalized; moreover, the allocation of labor into manufacturing and non-manufacturing is indeterminate. For any given $D_{m}^{i}$, however, the manufacturing output share of GDP is $\mu_{i}$, and the manufacturing export share of GDP (in country 1) is

$$
\varepsilon_{1}=\frac{L_{2}}{L_{w}} \times \frac{D_{m}^{1} F}{A_{m}(1-\rho) L_{1}}=\frac{L_{2}}{L_{w}} \mu_{1}
$$

where $L_{w}=L_{1}+L_{2}$. Exports are a fixed fraction of output with the fraction equaling country 2's share of the world labor endowment — a standard result from monopolistic competition models. Now, assume that relative country sizes do not change. Then, in terms of Figure 1, the model implies that — regardless of the pattern of manufacturing and non-manufacturing productivity

shocks (changes to $A_{n}$ and $A_{m}$ ) - (logarithmic) growth rates in the manufacturing output share of GDP and in the manufacturing export share of GDP should lie on the 45 degree line going through the origin. Both countries should be in the Northeast or the Southwest quadrants. As Figure 1 shows, this implication is clearly counterfactual. 


\section{IMPLICATIONS UNDER TRADE BARRIERS: PRODUCTIVITY SHOCKS}

With transport costs, the model's equilibrium is determinate. We consider two transport cost specifications, one in which transport costs only apply to manufactured goods, and one in which (uniform) transport costs apply to both types of goods. We first examine productivity shocks, and then we examine changes in transport costs.

When $\eta=\gamma=0$, expenditure shares are constant. Consequently, productivity shocks to the production functions for manufacturing and/or non-manufacturing goods have no effect on the share of expenditures on manufactured goods. Nor do they have any effect on the manufactured output share. To see the latter point, consider the specification in which only manufacturing goods are subject to transport costs. Then, $D_{m}^{i}$ changes proportionately with changes in manufacturing productivity (and not with changes in non-manufacturing productivity). Consequently, labor used in manufacturing is unchanged.

With more general preferences, analytical solutions do not exist, but solving the model numerically under a variety of assumptions yields the following results: When the price elasticity of demand exceeds $1(\eta>0)$, positive manufacturing productivity shocks lead to increases in the manufacturing output share of GDP and in the manufacturing export share of GDP in both countries. Non-manufacturing productivity shocks lead to the opposite outcome. When the price elasticity of demand is less than $1(\eta<0)$, the opposite implications obtain. This suggests that, for all sets of productivity shocks, and regardless of the demand elasticity, countries will lie either in the Northeast quadrant or the Southwest quadrant, but not in the Northwest quadrant. This is again highly counterfactual. 


\section{IMPLICATIONS UNDER TRADE BARRIERS: TRADE COST SHOCKS}

We study the effects of declining trade costs (globalization) for our two transport cost specifications. In our first specification - transport costs only on manufactured goods consider the case where $\eta=\gamma=0$. With more general preferences, the results are qualitatively similar. When the two countries have identical labor endowments, (global) decreases in trade barriers lead to no change in the manufacturing output share of GDP, but they lead to increases in the manufacturing export share of GDP. This continues to be counterfactual. When one country is smaller than the other country, lower trade barriers lead to a decline in the manufacturing output share of GDP and to an increase in the manufacturing export share of GDP. For the smaller country, this result is qualitatively consistent with the two facts. The decline in the manufacturing output share occurs via the home market effect. Lower trade barriers encourage the location of production in the larger market, which allows firms to minimize on transport costs. This result would seem to be consistent with the facts. The model also implies that the larger country would experience an increase in both its manufacturing output share and export share, however. More generally, in a multi-country model, such increases would occur in all large countries beyond a certain threshold. Figure 1 shows that the six largest economies in the OECD (the United States, Japan, Germany, France, Italy and Great Britain) all showed declines in their manufacturing output share of GDP. So the home market effect story is also counterfactual.

Our second transport cost specification - uniform transport costs on both types of goods — implies that manufacturing trade is balanced and that there is no trade in the nonmanufactured good. (See Davis 1998.) This implies that manufacturing output equals 
expenditure on manufactured goods in each country. In the case where $\eta=\gamma=0$, therefore, declines in transport costs have no effect on the manufacturing output share of GDP.

Under more general preferences, when the price elasticity of demand is less than 1 $(\eta<0)$, it is possible for both countries to suffer declines in the manufactured output share of GDP. The intuition here is straightforward. When trade costs fall, the manufactured bundle becomes cheaper. There is some substitution to manufactured goods, but because the demand elasticity is less than 1, the substitution is less than proportional. Expenditure on such goods falls as a share of GDP. Then, output on manufacturing falls, too. Meanwhile, manufacturing exports rise because trade costs fell.

This scenario suggests that it is possible to qualitatively replicate the puzzle facts: a globalization scenario in which trade costs on both types of goods decline, in conjunction with low demand elasticities of substitution, generates the two facts laid out in our introduction.

\section{DISCUSSION AND CONCLUSION}

While we have found a scenario that can qualitatively replicate the puzzle of increasing manufacturing export shares and declining manufacturing output shares, there remains the question of whether this scenario can quantitatively replicate it. We would conjecture that it would be difficult. The primary reason is that recent research by BK and by Yi (2003) show how difficult it is for standard one-sector trade models to explain the growth of world trade without resorting to elasticities of substitution between manufactured goods of about 10-15. In a two sector model, an additional elasticity, the elasticity of substitution between sectors, matters. To replicate our puzzle above, we need this elasticity to be less than 1 . But this would force the elasticity of substitution between manufactured goods to be even higher to explain the growth of 
trade.

Another possible scenario is one in which developing countries joined the global market in recent decades, and for comparative advantage reasons, this has led to a loss of some manufacturing from OECD countries to developing countries. This globalization scenario differs from ours because it emphasizes the OECD-non-OECD links, while we focus on intra-OECD links. While the forces in this scenario are undoubtedly occurring, we believe they may not be quantitatively important because, as BK shows, the share of intra-OECD trade in total OECD trade rose from abut $46 \%$ to $61 \%$ between 1961 and 1990 .

We conclude by suggesting an additional propagation mechanism, vertical specialization. We mean the phenomenon by which countries increasingly specialize in producing only particular stages of a good's production sequence so that a good crosses multiple borders while in process. Recent research has shown that this phenomenon is increasingly empirically important. $^{3}$

Vertical specialization has two implications that have bearing on our facts. The first is that trade data are double-counted because there is back-and-forth trade involving intermediate and final goods. The existing model does not take that into account because it has only final goods. Second, and perhaps more importantly, changes in productivity and in trade barriers affect specialization patterns, which affects the pattern of trade, even controlling for the doublecounting in trade. ${ }^{4}$

As an example, consider the effects of the U.S.-Canada Auto Pact of 1965. This pact eliminated trade barriers in motor vehicles, and auto parts and components. As a result, U.S.Canada auto trade surged, rising from about 8 percent of total U.S.-Canada trade to 30 percent in 
less than five years. Part of the increase was driven by the increasing returns to scale forces emphasized by the monopolistic competition model. As Hummels, Rapoport and Yi (1998) show, however, vertical specialization also played a significant role in accounting for the increase in trade. The United States now primarily exports motor vehicle parts to Canada and imports assembled vehicles embodying those U.S. parts. These parts are double-counted. The second implication is that, were it not for the decline in trade barriers, the entire vertical specialization trade pattern - parts exported to Canada, assembled vehicles imported from Canada - may never have occurred in the first place. An assessment of the quantitative importance of vertical specialization in explaining the puzzle is an interesting avenue of future research. $^{5}$ 


\section{REFERENCES}

Bergoeing, Raphael and Kehoe, Timothy J. "Trade Theory and Trade Facts." Federal Reserve Bank of Minneapolis Staff Report 284, October 2003.

Chen, Hogan and Kei-Mu Yi. "Trends in Vertical Specialization and International Trade." Manuscript. Federal Reserve Bank of New York, September 2003.

Davis, Donald R. “The Home Market, Trade, and Industrial Structure.” American Economic Review, December 1998, 88 (5), pp. 1264-76.

Helpman, Elhanan, and Paul R. Krugman. Market Structure and Foreign Trade: Increasing Returns, Imperfect Competition and the International Economy. Cambridge, MA: MIT Press, 1985.

Hummels, David, Ishii, Jun and Kei-Mu Yi. "The Nature and Growth of Vertical Specialization in World Trade.” Journal of International Economics, June 2001, 54 (1), pp. 75-96.

Hummels, David, Rapoport, Dana, and Kei-Mu Yi. "Vertical Specialization and the Changing Nature of World Trade.” FRBNY Economic Policy Review, June 1998, pp. 7999.

Spilimbergo, Antonio. “Deindustrialization and Trade,” Review of International Economics, 1998, 6 (3), pp. 450-60. 
Strauss-Kahn, Vanessa. "The Role of Globalization in the Within-Industry Shift Away from Unskilled Workers in France," forthcoming in Challenges to Globalization: Analyzing the Economics, Robert E. Baldwin and Alan L. Winters, Eds. University of Chicago Press.

Yi, Kei-Mu. “Can Vertical Specialization Explain the Growth of World Trade?” Journal of Political Economy. February 2003, 111 (1), pp. 52-102. 
Figure 1. Manufacturing Exports and GDP. Average Annual Change 1970-2001 (Percent)

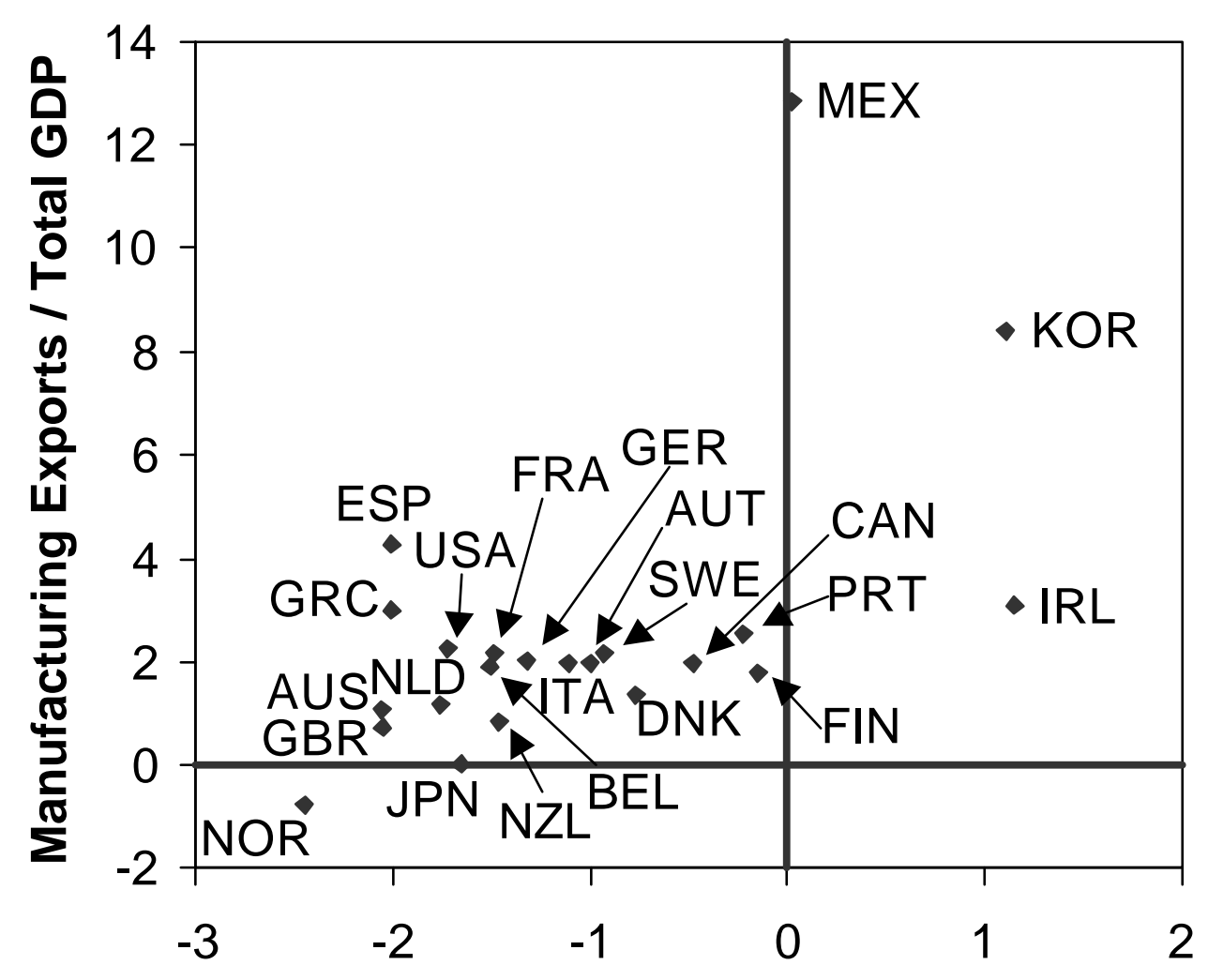

Manufacturing Value Added / Total GDP 


\section{ENDNOTES}

* Bergoeing: Centro de Economia Aplicada, Universidad de Chile, Av. Republica 701, Santiago de Chile, Chile. Kehoe: Department of Economics, University of Minnesota, and Federal Reserve Bank of Minneapolis, 271 19th Avenue South, Minneapolis, MN 55455. Strauss-Kahn: INSEAD, Boulevard de Constance, 77305, Fontainebleau Cedex, France. Yi: Research Department, Federal Reserve Bank of Philadelphia, 10 Independence Mall, Philadelphia, PA, 19106. We thank Matthew Kondratowicz and Kim Ruhl for excellent research assistance and Peter Schott for useful comments. The views expressed here are those of the authors and do not necessarily reflect the position of the Federal Reserve Banks of New York and Minneapolis or the Federal Reserve System.

\footnotetext{
${ }^{1}$ Among the 30 OECD countries, eight could not be included in our sample because data on manufacturing trade or GDP existed for less than 10 years. Hereafter, "OECD" will refer to the 22 countries for which we have long data. For most countries, the data run from 1970 to 2001 . When we use gross output instead of value added, we find the same pattern. We also examine three-digit industry level data for six of the G-7 countries. Most of the industries are in the "Northwest" quadrant. The data sources include OECD and UNCTAD publications. More details are available from the authors on request.

${ }^{2}$ Spilimbergo (1998) examines de-industrialization and trade in the context of a Ricardian model. ${ }^{3}$ See Strauss-Kahn (forthcoming); Hummels, Ishii, and Yi (2001); and Hummels, Rapoport, and Yi (1998), for example.
} 
${ }^{4}$ See Yi (2003) for a model in which lower trade barriers propagates trade via increased vertical specialization.

${ }^{5}$ Chen and Yi (2003) calculate the double-counting effect for manufacturing in the United States (using a more narrow definition of manufacturing than in the OECD data). They estimate that double-counted U.S. manufactured exports in 2000 were 198 billion dollars, or about 2.0 percent of U.S. GDP. The "value-added" manufacturing export share of GDP grew at about half of its officially reported rate. 